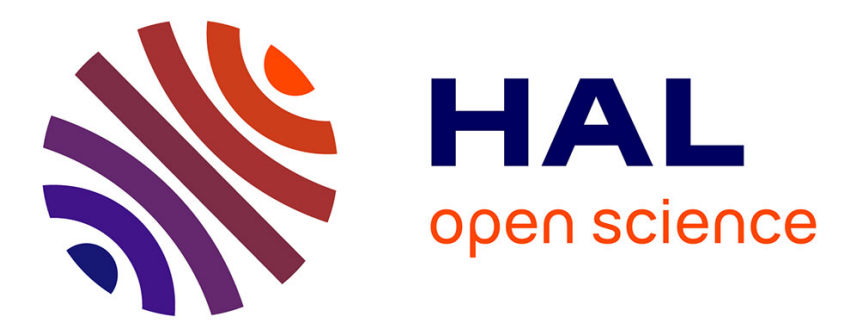

\title{
An Emergy Environmental Accounting-Based Study of Different Biofuel Production Systems
}

Maria Freitas Bueno, Cecília Almeida, Feni Agostinho, Sérgio Ulgiati, Biagio

Fernando Giannetti

\section{- To cite this version:}

Maria Freitas Bueno, Cecília Almeida, Feni Agostinho, Sérgio Ulgiati, Biagio Fernando Giannetti. An Emergy Environmental Accounting-Based Study of Different Biofuel Production Systems. IFIP International Conference on Advances in Production Management Systems (APMS), Sep 2016, Iguassu Falls, Brazil. pp.876-883, 10.1007/978-3-319-51133-7_103 . hal-01615703

\section{HAL Id: hal-01615703 \\ https://hal.inria.fr/hal-01615703}

Submitted on 12 Oct 2017

HAL is a multi-disciplinary open access archive for the deposit and dissemination of scientific research documents, whether they are published or not. The documents may come from teaching and research institutions in France or abroad, or from public or private research centers.
L'archive ouverte pluridisciplinaire HAL, est destinée au dépôt et à la diffusion de documents scientifiques de niveau recherche, publiés ou non, émanant des établissements d'enseignement et de recherche français ou étrangers, des laboratoires publics ou privés. 


\title{
An Emergy Environmental Accounting-Based Study of Different Biofuel Production Systems
}

\author{
Maria de Fátima de Freitas Bueno ${ }^{1,2}$, Cecília Maria Villas Bôas Almeida ${ }^{2}$, \\ Feni Agostinho ${ }^{2}$, Sérgio Ulgiati ${ }^{3}$, and Biagio Fernando Giannetti ${ }^{2}$ \\ ${ }^{1}$ Federal Institute of South of Minas Gerais Inconfidentes, Brazil \\ fatima.bueno@ifsuldeminas.edu.br \\ 2 Paulista University, São Paulo, Brazil \\ 3 University of Naples, Italy
}

\begin{abstract}
At the same time that the expectations grow around sustainable energy generation, biofuels emerge as an alternative to fossil fuels. This study evaluates the use of resources in the different biofuel production systems based on the emergy ternary diagram. A set of indicators was incorporated to the evaluation, aiming to display the environmental performance of each system. Results indicated that most of the analyzed systems are highly dependent on economy-sourced resources, evidencing that in a long term, there is no sustainable system. However, one of the public managers' aims is to search for a means to indicate which policies and patterns are sustainable for humanity and nature. Since economic development is dependent of the resources it uses, emergy accounting may be used as a tool in the process of selecting plans for sustainable development.
\end{abstract}

Keywords: Emergy · Biofuels · Indicators · Ternary diagram

\section{Introduction}

This paper reproduces part of a $\mathrm{Ph} . \mathrm{D}$. thesis under construction, and it is related to the emergy methodology robustness [1], and uses the ternary diagram [2] as a main tool in the biofuels evaluation.

Biofuels have emerged as a promising alternative to fossil fuels, they can be produced from a widely varied range of inputs. The most used are those from agricultural crops and their demand have been increased considerably. Nevertheless, their sustainability have been the object of many discussions [3,4]. In this sense, a large number of studies have been carried out in search for the most sustainable crop for biofuel production. Takahashi and Ortega [5] have presented the emergy analyses of five crops perceived as feasible feedstocks for biodiesel production. Ren et al [6] have developed a capable mathematical model of evaluating the sustainability of bio-diesel supply chains produced from multiple-inputs and helping decision-makers choose the most sustainable model. Dong et al [7] have performed an emergy and energy analysis of a typical distillery system. Ren et al [8] have analyzed the sustain-ability of five different biodiesel production 
systems under a life-cycle perspective. Triana [9] has reviewed four studies by different authors with different approaches, and compared the results of bioethanol produced from sugarcane. Agostinho and Ortega [10] have performed a multicriteria evaluation of environmental and energy aspects of an integrated food, energy, and environmental services production system on a small-scale. Lu et al [11] have carried out an integrated evaluation between economic and emergy cost-benefit of ethanol production from rice. Pereira and Ortega [12] have assessed large-scale production of ethanol from sugarcane. Seghetta et al [13] have investigated potential production of bioethanol from macroalgae, compared to conventional system. Goh and Lee [14] have studied the possibility to create a renewable and sustainable energy source, using emergy evaluation methodology and energy from palm oil. Bastianoni et al [15] have evaluated the use of two types of renewable inputs to produce biodiesel. Cruz and Nascimento [16] have performed an emergy analysis of oil production from microalgae. Yang et al [17] have evaluated ethanol production from cassava. Cavalett and Ortega [18] have assessed the environmental impact of biodiesel production from soybeans. Felix and Tilley [19] have studied ethanol production from cellulose sources. Liu et al [20] have compared petroleum production sustainability and two scenarios of ethanol production from rice. Emergy accounting has been used in the production systems assessment on all studies mentioned above.

Emergy is a real wealth measure, in terms of calculating the energy required for the production system. Odum [21] has defined emergy as the available solar energy used directly and indirectly to make a product or service. Its unit is the solar emjoule (sej).

The emergy methodology helps to identify and measure all inflows into a system, and it considers energy use aspects that are not considered in other methodologies, for instance natural resources, labor, and ecosystem services [22,23].

The ratio of the total emergy used by product energy results in a transformation coefficient, named transformity, whose dimensions are sej/J [24] and it is used to convert items from different scales into a common base. Consequently, different systems can be compared.

Albeit several biofuel production systems assessments are available in literature, none of those exhibit a wider discussion comparing fully different systems and presenting results in the form of graphs. Especially in the ternary diagram case, in which presents itself as a powerful tool that allows for a prompt and efficient interpretation of results, providing very important information to researchers and decision-makers [1]. Consequently, the aim of this study is to use the emergy ternary diagram to assess different biofuel production systems, mainly as for use of resources.

\section{Methodology}

This study was organized using an emergy databank, developed as part of a Doctorate project. The following actions were accomplished: data collection, cal- 
culation of emergy indicators, and application of collected data into the ternary diagram.

\subsection{Data Collection}

Data used in this study are from biofuels production systems assessments using emergy environmental accounting, and were organized to facilitate their interpretation. The feedstock for biofuel production, study site, baseline, unit, the product energy, transformity, emergy, and input flows were the used data in this study. However, emergy and transformity values may vary according to the analyst's choices, and also vary with the adopted baseline. Therefore, all emergy and input flows values herein have been adjusted to a common baseline (15.83 x $10^{24} \mathrm{sej} / \mathrm{yr}[25,26]$ to allow comparisons.

\subsection{Emergy Indicators Calculation}

Collected data were tabulated and adjusted, and then the emergy indicators were calculated, based on input flows.

The input flows that are necessary to maintain the system are divided into three resources categories: renewable $(\mathrm{R})$, non-renewable $(\mathrm{N})$ and economy feedback $(\mathrm{F})$. The $\mathrm{R}$ and $\mathrm{N}$ resources are provided by the environment and are economically free; however, the $\mathrm{R}$ flows have temporal and spatial renovation cycle capacity faster than its consumption cycle. Examples of R flows include the sun, the wind, the rain and so forth. The consumption cycle of $\mathrm{N}$ flows supersedes its renovation cycle. Examples of $\mathrm{N}$ flows include the soil, timber, mining resources and so forth. The $\mathrm{F}$ flows are associated with services and goods provided by economic system, or resources from other regions outside the system boundaries [2,27]. Examples of F flows include fuels, fertilizers, services and so forth.

Resources flows allow for the calculation of different indicators that may help to analyze or to oversee a production system. Information on indicators based on emergy can be found on [21]. The indicators that were used herein are presented below:

EYR (Emergy Yield Ratio) is the ratio between the total emergy of a product $(\mathrm{Y}=\mathrm{R}+\mathrm{N}+\mathrm{F})$ by the emergy of $\mathrm{F}$ flows (Equation 1) and represents the emergy return on the economic investment. Therefore, it reflects the ability of the process to explore local resources [2,28], nevertheless it does not differentiate $\mathrm{R}$ and $\mathrm{N}$ resources.

$$
E Y R=\frac{Y}{F}=\frac{R+N+F}{F}
$$

ELR (Environmental Load Ratio) is the ratio between the emergy of $\mathrm{F}$ and $\mathrm{N}$ inputs by the emergy R inputs (Equation 2). ELR is an indicator of the process pressure on the local ecosystem due to production activities [2]. An elevated ELR ratio may indicate a stress on the utilization of $\mathrm{R}$ flows [28].

$$
E L R=\frac{N+F}{R}
$$


ESI (Emergy Sustainability Index) is the ratio between emergy yield by the environmental load index (Equation 3). The concept of sustainability is linked to the EYR maximization and the ELR minimization, i.e. maximum use of the investment with minimum stress on local resources $[2,27]$. This index may be used to value the $\mathrm{N}$ investments in order to maximize the system effectiveness.

$$
E S I=\frac{E Y R}{E L R}=\frac{Y / F}{(N+F) / R}
$$

\subsection{Ternary Diagram}

The emergy ternary diagram has been used in this study, aiming at a clearer presentation of the results.

The ternary diagram consists in an equilateral triangle with three variables associated with percentages. Each one of the vertices relates to a flow (R, N or $\mathrm{F}$ ), and the sides represent binary combinations in the form of dots within the triangle internal boundaries. Full information on this tool are available on [2] and $[27]$.

Using equilateral triangle properties provides further information on the studied system dependence on a given type of flow (either $\mathrm{R}, \mathrm{N}$ or $\mathrm{F}$ ), over the system's (eco) efficiency as for usage of reserves, and efficiency in supporting the environment, necessary to the system operation [2]. It also presents emergy indicators calculations and corroborates the emergy methodology robustness [1].

\section{Results and discussion}

Table 1 shows the production systems evaluated in this study. The flows that were used in biofuel production, in conjunction with the three calculated emergy indicators are displayed. Labor and services resources were not considered in the calculations. Value interval for every indicator assessed herein was as suggested by $[24]$.

As shown in the Table 1, a large part of the systems have EYR lower than 5, indicating an expressive use of F flows; furthermore, systems with EYR lower than 2 do not contribute enough to be considered energy sources, consequently acting more as consumers. In biofuels case, only the four systems with EYR higher than 5 are considered as primary energy sources, as those groups are capable of advantageously using environmental resources.

Most systems have ELR higher than 10. This means that those systems impact on the environment, are relatively concentrated, resulting from large investments, probably of $\mathrm{N}$ inputs, in a restricted area. Systems with ELR between 2 and 10 are considered moderate and those with ELR lower than 2 have low environmental load.

From the presented systems, only the bioethanol production system from macroalgae, in Denmark, has EYR and ELR adjusted for better use of R resources. The EYR is high, followed by a low ELR, indicating low environmental 
strain. On the other hand, around $40 \%$ of the systems have a low EYR, combined with a high ELR, consequently suggesting the occurrence of environmental stress.

Finally, it is noticeable that most systems (about 70\%) features sustainability indexes lower than 1 . The ESI of the bioethanol production system from macroalgae, in Denmark, deserves special attention, as it is the only long term sustainable system, among all. That system presents sustainability level of 59.75 , probably due to the use of $\mathrm{R}$ resources in algae transportation, which, in this case is the energy from the sea waves, consequently avoiding use of fossil fuels, which is the resource used for that purpose in other systems.

Table 1. Biofuel production systems and their respective indicators

\begin{tabular}{lllll}
\hline \multicolumn{1}{c}{ Biofuel } & EYR & ELR & ESI & Ref. \\
\hline Ethanol from sugarcane - South Florida & 5.84 & 3.93 & 1.49 & {$[29]$} \\
Ethanol from grape - Italy & 5.10 & 5.16 & 0.99 & {$[29]$} \\
Oil from sunflower - Italy & 1.43 & 2.51 & 0.57 & {$[15]$} \\
Oil from macroalgae - Italy & 2.71 & 1.99 & 1.36 & {$[15]$} \\
Bioethanol from sugarcane - Brazil & 2.00 & 7.66 & 0.26 & {$[28]$} \\
Ethanol from sugarcane - South Florida & 5.33 & 10.26 & 0.52 & {$[30]$} \\
Biodiesel from soybean - Brazil & 1.94 & 1.57 & 1.23 & {$[18]$} \\
Oil from microalgae - Texas & 1.12 & 8.63 & 0.13 & {$[16]$} \\
Ethanol from corn - Italy & 1.25 & 6.11 & 0.20 & {$[7]$} \\
Ethanol from wheat - China & 1.47 & 5.36 & 0.27 & {$[7]$} \\
Ethanol from switchgrass - Iowa & 1.43 & 2.69 & 0.53 & {$[19]$} \\
Oil from palm - Malaysia & 1.24 & 4.55 & 0.27 & {$[14]$} \\
Bioethanol rice+straw +chaff - Japan & 1.06 & 17.00 & 0.06 & {$[11]$} \\
Bioethanol from rice - Japan & 1.07 & 15.15 & 0.07 & {$[11]$} \\
Ethanol from rice - Japan & 1.10 & 20.99 & 0.05 & {$[11]$} \\
Oil from palm - Thailand & 2.96 & 1.38 & 2.14 & {$[31]$} \\
Oil from jatropha - Thailand & 2.29 & 1.80 & 1.28 & {$[31]$} \\
Ethanol from sugarcane - Brazil & 1.99 & 1.36 & 1.46 & {$[12]$} \\
Bioethanol from macroalgae - Italy & 1.67 & 1.49 & 1.12 & {$[13]$} \\
Bioethanol from macroalgae - Denmark & 8.25 & 0.14 & 59.75 & {$[13]$} \\
Biodiesel from palm - China & 1.03 & 58.65 & 0.02 & {$[8]$} \\
Biodiesel from sunflower - China & 1.07 & 24.71 & 0.04 & {$[8]$} \\
Biodiesel from soybean - China & 1.09 & 17.05 & 0.06 & {$[8]$} \\
Biodiesel from rapeseed - China & 1.04 & 40.85 & 0.03 & {$[8]$} \\
Biodiesel from jatropha - China & 1.01 & 223.59 & 0.00 & {$[8]$} \\
Fuel from cassava - China & 1.07 & 15.11 & 0.07 & {$[17]$} \\
Biodiesel from soybean - China & 1.11 & 13.41 & 0.08 & {$[6]$} \\
Biodiesel from rapeseed - China & 1.05 & 29.99 & 0.03 & {$[6]$} \\
Biodiesel from sunflower - China & 0.08 & 20.04 & 0.05 & {$[6]$} \\
\hline
\end{tabular}

These results, based on the values of flows $\mathrm{R}, \mathrm{N}$, and $\mathrm{F}$ are better visualized from ternary diagram, which also allows us for a comparison among the various configurations shown on the biofuels production systems (Figure 1). 
The Figure 1 exhibits two sustainability lines that divide the graph into three parts. The area below the index equal to $1(\mathrm{ESI}<1)$ indicates the long term nonsustainable systems. The area between indices 1 and $5(1<\mathrm{ESI}<5)$ characterizes mid term sustainability. The area above the index equal to 5 (ESI $>5$ ) means long term sustainability. Three groups of biofuel production systems were identified in Figure 1, considering sustainability and resource inflows.

The group 1 shows the systems that have a strong dependence on F resources, mainly of products derived from fossil fuels, such as fertilizers. These systems are not considered sustainable in the long term.

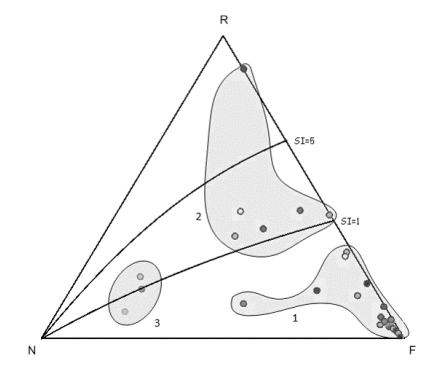

Fig. 1. Emergy ternary diagram of the biofuels production systems: (1) soybean, sunflower, rapeseed, rice, corn, wheat, switchgrass, cassava, microalgae, palm, jatropha, sugarcane, (2) macroalgae, jatropha, palm, sugarcane, (3) sugarcane, grape.s

However, systems with low or no dependence on such resources are sought after, and that explains the presence, on the Figure 1, of dots related to studies that involve sustainability assessments of non-conventional inputs for more sustainable biofuels production, such as macroalgae, jatropha and palm (group 2). These systems are considered as mid and long term sustainable.

Biofuels produced from grapes, and, in some cases, from sugarcane, are also characterized as mid-term sustainable, despite presenting high consumption of $\mathrm{N}$ resources (group 3 ).

Therefore, the dots in Figure 1 show that biofuels produced from food crops, mainly, can not be considered long term sustainable (group 1 and group 3). Consequently, production systems that use non-conventional flows present themselves as more sustainable (group 2).

\section{Conclusion}

It is clear enough that dependence on $\mathrm{N}$ and $\mathrm{F}$ resources enhances environmental degradation, rendering the system relatively less sustainable. Consequently, the search for inputs for biofuels production that can replace fossil fuels remains a challenge, since it is necessary that they provide a net energy gain, that be sustainable, that feature a higher environmental benefit than the fossil fuel that 
they are intended to replace, that be economically competitive, and that be able to be produced in large quantities.

Such set of information can be obtained from an emergy analysis. However, graphic presentations are most convenient when it comes to visualize results. The interpretation of results and comparisons between systems is easier and faster with the application from the emergy ternary diagram (Figure 1). Moreover, the emergy ternary diagram corroborates the robustness of the emergy accounting methodology by displaying the dots of studied systems in well-defined regions, with some plainly justifiable exceptions.

Acknowledgements. We are greatful for Universidade Paulista (UNIP) for the financial support, and for the Instituto Federal de Educação, Ciência e Tecnologia do Sul de Minas Gerais. We also want to thank to the CAPES-PROSUP for the scholarship provided to the first author.

\section{References}

1. Giannetti, B., Almeida, C., Agostinho, F., Bonilla, S., Ulgiati, S.: Primary Evidences on the Robustness of Environmental Accounting from Emergy. J Environ Acc Manag 1(2), 203-212 (2013)

2. Giannetti, B., Barrella, F., Almeida, C.: A Combined Tool for Environmental Scientists and Decision Makers: Ternary Diagrams and Emergy Accounting. Journal of Cleaner Production 14(2), 201-210 (2006)

3. Liao, W., Heijungs, R., Huppes, G.: Is Bioethanol a Sustainable Energy Source? An Energy-, Exergy-, and Emergy-based Thermodynamic System Analysis. Renewable Energy 36(12), 3479-3487 (2011)

4. Milazzo, M., Spina, F., Primerano, P., Bart, J.: Soy Biodiesel Pathways: Global Prospects. Renewable and Sustainable Energy Reviews 26, 579-624 (2013)

5. Takahashi, F., Ortega, E.: Assessing the Sustainability of Brazilian Oleaginous Crops-Possible Raw Material to Produce Biodiesel. Energy Policy 38(5), 2446$2454(2010)$

6. Ren, J., Tan, S., Yang, L., Goodsite, M.E., Pang, C., Dong, L.: Optimization of Emergy Sustainability Index for Biodiesel Supply Network Design. Energy Conversion and Management 92, 312-321 (2015)

7. Dong, X., Ulgiati, S., Yan, M., Zhang, X., Gao, W.: Energy and EMergy Evaluation of Bioethanol Production from Wheat in Henan Province, China. Energy Policy 36(10), 3882-3892 (2008)

8. Ren, J., Manzardo, A., Mazzi, A., Fedele, A., Scipioni, A.: Emergy Analysis and Sustainability Efficiency Analysis of Different Crop-based Biodiesel in Life Cycle Perspective. The Scientific World Journal 2013 (2013)

9. Triana, C.A.R.: Energetics of Brazilian Ethanol: Comparison Between Assessment Approaches. Energy Policy 39(8), 4605-4613 (2011)

10. Agostinho, F., Ortega, E.: Integrated Food, Energy and Environmental Services Production as an Alternative for Small Rural Properties in Brazil. Energy 37(1), 103-114 (2012)

11. Lu, H., Lin, B.L., Campbell, D.E., Sagisaka, M., Ren, H.: Biofuel vs. Biodiversity? Integrated Emergy and Economic Cost-benefit Evaluation of Rice-ethanol Production in Japan. Energy 46(1), 442-450 (2012) 
12. Pereira, C.L., Ortega, E.: Sustainability Assessment of Large-scale Ethanol Production from Sugarcane. Journal of Cleaner Production 18(1), 77-82 (2010)

13. Seghetta, M., Østergård, H., Bastianoni, S.: Energy Analysis of Using Macroalgae from Eutrophic Waters as a Bioethanol Feedstock. Ecol. Modelling 288, 25-37 (2014)

14. Goh, C.S., Lee, K.T.: Palm-based Biofuel Refinery (PBR) to Substitute Petroleum Refinery: an Energy and Emergy Assessment. Renewable and Sustainable Energy Reviews 14(9), 2986-2995 (2010)

15. Bastianoni, S., Coppola, F., Tiezzi, E., Colacevich, A., Borghini, F., Focardi, S.: Biofuel Potential Production from the Orbetello Lagoon Macroalgae: A Comparison with Sunflower Feedstock. Biomass and Bioenergy 32(7), 619-628 (2008)

16. da Cruz, R.V.A., do Nascimento, C.A.O.: Emergy Analysis of Oil Production from Microalgae. Biomass and Bioenergy 47, 418-425 (2012)

17. Yang, H., Chen, L., Yan, Z., Wang, H.: Emergy Analysis of Cassava-based Fuel Ethanol in China. Biomass and Bioenergy 35(1), 581-589 (2011)

18. Cavalett, O., Ortega, E.: Integrated Environmental Assessment of Biodiesel Production from Soybean in Brazil. Journal of Cleaner Production 18(1), 55-70 (2010)

19. Felix, E., Tilley, D.R.: Integrated Energy, Environmental and Financial Analysis of Ethanol Production from Cellulosic Switchgrass. Energy 34(4), 410-436 (2009)

20. Lin, B.L., Sagisaka, M., et al.: Sustainability Assessment of Bioethanol and Petroleum Fuel Production in Japan Based on Emergy Analysis. Energy Policy 44, 23-33 (2012)

21. Odum, H.T.: Environmental Accounting. Wiley (1996)

22. Patrizi, N., Pulselli, F.M., Morandi, F., Bastianoni, S.: Evaluation of the Emergy Investment Needed for Bioethanol Production in a Biorefinery Using Residual Resources and Energy. Journal of Cleaner Production 96, 549-556 (2015)

23. Wang, X., Chen, Y., Sui, P., Gao, W., Qin, F., Zhang, J., Wu, X.: Emergy Analysis of Grain Production Systems on Large-scale Farms in the North China Plain Based on LCA. Agricultural Systems 128, 66-78 (2014)

24. Brown, M., Ulgiati, S.: Emergy Evaluations and Environmental Loading of Electricity Production Systems. Journal of Cleaner Production 10(4), 321-334 (2002)

25. Odum, H.T., Brown, M., Williams, S.: Handbook of Emergy Evaluation. A Compendium of Data for Emergy Computation. Introduction and Global Budget. University of Florida, Gainesville (2000)

26. Odum, H.T.: Handbook of Emergy Evaluation. A Compendium of Data for Emergy Computation. Emergy of Global Processes. University of Florida, Gainesville (2000)

27. Almeida, C., Barrella, F., Giannetti, B.: Emergetic Ternary Diagrams: Five Examples for Application in Environmental Accounting for Decision-making. Journal of Cleaner Production 15(1), 63-74 (2007)

28. Brown, M., Ulgiati, S.: Emergy-based Indices and Ratios to Evaluate Sustainability: Monitoring Economies and Technology Toward Environmentally Sound Innovation. Ecological Engineering 9(1), 51-69 (1997)

29. Bastianoni, S., Marchettini, N.: Ethanol Production from Biomass: Analysis of Process Efficiency and Sustainability. Biomass and Bioenergy 11(5), 411-418 (1996)

30. Ulgiati, S., Brown, M., Bastianoni, S., Marchettini, N.: Emergy-based Indices and Ratios to Evaluate the Sustainable Use of Resources. Ecol. Eng. 5(4), 519-531 (1995)

31. Nimmanterdwong, P., Chalermsinsuwan, B., Piumsomboon, P.: Emergy Evaluation of Biofuels Production in Thailand from Different Feedstocks. Ecological Engineering 74, 423-437 (2015) 